\title{
The Show Must Go On
}

\section{The Effects of Crisis on Health-Oriented Leadership and Follower Exhaustion During the COVID-19 Pandemic}

\author{
Laura Klebe(i), Katharina Klug, and Jörg Felfe \\ Helmut Schmidt University / University of the Federal Armed Forces Hamburg, Germany
}

\begin{abstract}
By disrupting routines at work, the Covid-19 pandemic may have undermined the extent and effectiveness of health-oriented leadership (HoL) in terms of staff-care and self-care. In a survey with two measurement points in the spring of $2020\left(N_{\mathrm{t} 1}=264 ; N_{\mathrm{t} 2}=123\right)$, we examined whether the stronger the crisis the lower $\mathrm{HoL}$ is, while becoming more effective in terms of follower health. Crisis severity turned out to be indirectly related to exhaustion via staff-care and self-care. Staff-care was more effective for follower health the stronger the crisis was. The results were largely supported in a subsample when exhaustion was measured 1 week later. Moreover, the Covid-19 pandemic was indirectly related to crisis severity via hindrance stressors. Findings underline that staff-care was jeopardized but gained in importance during the pandemic. By displaying staff-care, leaders can buffer negative crisis effects on followers. Organizations should strengthen HoL to protect the health of both leaders and followers during crises.
\end{abstract}

Keywords: COVID-19, health-oriented leadership, crisis, health

\begin{abstract}
The Show Must Go On: Die Effekte gesundheitsorientierter Führung auf die Mitarbeitergesundheit in der COVID-19 Pandemie
Zusammenfassung: Die COVID-19 Pandemie ist für viele Beschäftigte mit erheblichen Risiken verbunden. In einer Fragebogenstudie mit zwei Messzeitpunkten ( $N_{\mathrm{t} 1}=264 ; N_{\mathrm{t} 2}=123$ ) wurde im Frühjahr 2020 untersucht, ob in dieser Krise weniger Staff-Care und Self-Care gezeigt wird, aber die Bedeutung von Staff-Care für die Mitarbeitergesundheit möglicherweise an Bedeutung gewinnt. Je mehr die Pandemie als Krise erlebt wurde, desto geringer waren Staff-Care und Self-Care, und umso höher war die Erschöpfung. Staff-Care war für die Gesundheit umso wichtiger, je stärker die Krisensituation eingeschätzt wurde. Weitestgehend die gleichen Zusammenhänge zeigten sich auch wenn Erschöpfung zu einem späteren Zeitpunkt gemessen wurde. Darüber hinaus konnte der Zusammenhang zwischen der Pandemie und dem Ausmaß der Krisensituation durch spezifische Stressoren am Arbeitsplatz erklärt werden. Die Ergebnisse zeigen, dass gesundheitsförderliche Führung in der Pandemie zwar abnimmt, aber in Krisensituationen an Bedeutung gewinnt. Durch gesundheitsförderliche Mitarbeiterführung können Führungskräfte krisenbedingte Risiken abmildern.
\end{abstract}

Schlüsselwörter: COVID-19, gesundheitsförderliche Führung, Krise, Gesundheit

Positive leadership represents an important workplace resource for maintaining and improving employee health (Ahmed et al., 2020). However, by interrupting regular working processes, the COVID-19 pandemic had sudden and profound effects on the working environment and well-being of employees worldwide (Luceño-Moreno et al., 2020; Nicola et al., 2020). Consequently, leaders and employees may have to deal with hindrance stressors (e.g., reorganization of work routines, stalled projects), which may impede both health-promoting leadership and employee well-being (LePine et al., 2005).

This study investigates health-specific leadership in crisis by referring to the framework of health-oriented leadership (HoL; Franke et al., 2014; Pundt \& Felfe, 2017). Health-oriented leadership includes the follower-directed behavior of leaders in terms of staff-care (i.e., the extent to which leaders value, are aware of, and protect follower health at work), and leader and follower self-care (i.e., the extent to which they value, are aware of, and protect their own health). Previous studies supported the construct validity and revealed positive effects of HoL under routine conditions (Arnold \& Rigotti, 2021; Franke et al., 2014; Horstmann, 2018; Klug et al., 2019). However, to which extent crises affect HoL is presently unclear.

Crises reflect a relevant context factor that challenges leadership through different mechanisms (Halverson et al., 2004; Hannah et al., 2009). First, it is unclear whether leaders reduce or even strengthen their effort to engage in staff-care when a crisis becomes more severe. It is conceivable that leaders strengthen health-oriented behaviors to appreciate and support the health of followers in critical times. But it may be more likely that leaders withdraw from health-oriented behavior because they lack the capacities for staff-care (Hobfoll, 1989; Hobfoll et 
al., 2018). Reduced staff-care would imply a loss of resources for followers, who in turn may reduce self-care with negative consequences for their health.

Second, it is unclear whether HoL will be more or less effective when a crisis becomes more severe. On the one hand, crisis severity may overshadow and thus reduce the positive effects of health-oriented behavior; on the other hand, HoL may become particularly important because follower health is at risk in crisis (Mucci et al., 2016). Because of increasing demands and work-related hindrances, employees may have a greater need for staff-care in crisis and will benefit even more than under normal circumstances (de Hoogh et al., 2004; Waldman et al., 2001) - which would be in line with the "gain paradox principle" suggested by Hobfoll et al. (2018) .

Third, the COVID-19 pandemic does not affect all organizations equally, so that crisis severity likely differs among employees. Crisis severity may depend on how strongly the pandemic affects work in terms of concrete hindrances in everyday work routines (e.g., increasing hassles, stagnation, or ambiguity; Cavanaugh et al., 2000; Nicola et al., 2020). Followers whose work is more affected by the pandemic likely report more hindrances, higher crisis severity, and consequently less health-oriented leadership.

Drawing on the conservation of resources theory (COR, Hobfoll, 1989) and the event systems theory (Morgeson et al., 2015), this study investigates crisis severity (the general level of threat and/or uncertainty at the workplace) as a situational influence for HoL in the context of the COVID-19 pandemic. We consider different mechanisms and in line with the gain paradox principle argue that crisis severity is associated with lower staff-care while at the same time strengthening its effectiveness regarding health. We investigate (1) whether crisis severity relates to lower staff-care, which in turn relates to lower follower self-care and higher exhaustion, and (2) whether crisis severity moderates the negative relationship between staff-care and follower exhaustion. To understand the extent to which these mechanisms are related to the pandemic, the study investigates whether work affected by the COVID-19 pandemic (hereinafter referred to as "COVID-19") relates to crisis severity via hindrance stressors.

The contribution of this approach is three-fold: First, the study contributes to the current debate on the effects of the COVID-19 pandemic and provides first empirical evidence of leadership effectiveness during the crisis in terms of follower health (Brammer \& Clark, 2020; Budhwar \& Cumming, 2020; Rudolph, Allan et al., 2020). Second, by investigating direct and indirect relationships between crisis severity, leadership, and follower health, the study expands our knowledge about situational influences of health-oriented leadership. Third, from a methodological perspective, the design with two measurement points extends previous cross-sectional studies on HoL and strengthens the existing validity of the HoL model. From a practical perspective, it provides a better understanding of the pathways through which the pandemic affects employees, which enables tailored trainings and interventions to maintain and promote employee health.

\section{Health-Oriented Leadership}

In a crisis, effective leadership is required to ensure the survival of organizations (Mumford et al., 2007), also by fostering follower health. Mechanisms through which leaders influence follower health can be captured in domain-specific leadership concepts, which explain follower health more specifically than general leadership constructs (Franke et al., 2014). Our study is based on the concept of HoL as introduced by Franke et al. (2014): Health-oriented leadership differentiates staff-care (i.e., health-promoting employee-directed leadership) from both leaders' and followers' self-care (i.e., health-promoting self-leadership). Both staff-care and self-care contribute to follower health, and each consist of three subdimensions: (1) Value (attitudes and value orientation toward health), (2) awareness (e.g., perception of healthrelated warning signals), and (3) behavior (concrete health-promoting actions, such as improving work organization; Franke et al., 2014).

In the past, healthy leadership constructs were criticized in leadership research. The review by Rudolph, Murphy et al. (2020) criticizes that behaviors defined as "healthy leadership" are conflated with the outcomes health and well-being, and that studies on healthy leadership suffer from insufficient methodologies or from "phantom validation." However, a growing number of studies support the relevance of the HoL model in particular (Arnold \& Rigotti, 2021; Franke et al., 2014; Horstmann, 2018; Kaluza et al., 2021; Klebe et al., 2021; Klug et al., 2019; Köppe et al., 2018). Research shows that staff-care relates to other relevant leadership criteria such as commitment, job satisfaction, performance, or engagement (Kaluza et al., 2021; Klebe et al., 2021; Pundt \& Felfe, 2017). Staff-care has also been shown to be empirically distinct from and to explain variance in health above and beyond other leadership constructs (Franke et al., 2014; Kaluza et al., 2021; Vincent-Höper \& Stein, 2019). Regarding the criticism of poor methodology, a growing number of studies are using experimental (Kaluza et al., 2021; Klebe et al., 2021) or longitudinal designs 
(Arnold \& Rigotti, 2021; Franke et al., 2014; Köppe et al., 2018), which further contributes to the validation of health-oriented leadership.

In line with COR theory (Hobfoll et al., 2018), the component staff-care of the HoL concept reflects an external resource for followers as leaders provide healthpromoting working conditions and support, fostering follower health (Franke et al., 2014). Staff-care is positively related to job resources, job satisfaction, and affective organizational commitment, and negatively related to stressors (Franke et al., 2014; Pundt \& Felfe, 2017). Because staff-care also fosters follower health by motivating followers to engage in health-promoting selfleadership, staff-care is positively related to follower selfcare (Franke et al., 2014; Horstmann, 2018). Follower self-care, in turn, reflects an internal resource that helps followers to protect and maintain their own health (Franke et al., 2014; Hobfoll et al., 2018). Self-care is positively related to general health and negatively to irritation, health complaints, presenteeism, and workfamily conflict (Franke et al., 2014; Pundt \& Felfe, 2017). Regarding follower strain in terms of exhaustion, we hypothesize the following:

Hypothesis 1a: Staff-care is negatively related to exhaustion.

Hypothesis 1b: Staff-care is positively related to self-care.

Hypothesis 1c: Self-care is negatively related to exhaustion.

\section{Crisis and Follower Health}

Aside from impacting leadership, crises can be expected to directly affect employee health. The COVID-19 pandemic is one of the most severe crises of the $21^{\text {st }}$ century and has impacted people's work and well-being (Ahmed et al., 2020; Trougakos et al., 2020). A crisis is defined as a suddenly occurring, threatening, or harmful event. According to Bundy and Pfarrer (2015) and Pillai (1996), crises interfere with normal operations of organizations, generating negative perceptions and uncertainty among those affected. As event systems theory states (Morgeson et al., 2015), crises can be considered novel, critical, and disruptive events that can occur on every organizational level, from individual employees and their teams to the external environment. The COVID-19 pandemic poses a prime example of a far-reaching global crisis. However, the extent to which the pandemic poses a threat and disruption to work routines varies depending on the organizations and their employees. Whereas some sectors or occupations are less affected (e.g., office jobs with wellestablished opportunities to work from home), others are strongly affected (e.g., hospitals; Nicola et al., 2020).
Schools have had to deal with temporary closure, tourism faces declining demands because of travel restrictions, and supermarkets have had to deal with increasing workloads because of increased demands (Nicola et al., 2020).

Because the pandemic does not affect all employees equally, we take into account the degree of crisis severity defined as the level of pressure, threat, and uncertainty in the respective working situation. Because it threatens followers' resources, the crisis severity poses a stressor (Demerouti et al., 2001; Hobfoll et al., 2018), with likely negative effects on employee health. For example, during the current pandemic, psychological distress and depressive symptoms increased among medical staff (Galbraith et al., 2020; Luceño-Moreno et al., 2020).

Overall, a crisis is a powerful stressor in the workplace with negative consequences for employee health (Ahmed et al., 2020; Luceño-Moreno et al., 2020). Consequently, we expect that followers who report higher crisis severity suffer from more exhaustion:

Hypothesis 2: Crisis severity is positively related to exhaustion.

\section{The Role of Crises for Health-Oriented Leadership}

While there is empirical evidence for the positive influence of HoL on followers, less is known about situational factors that promote or hinder health-oriented leadership, such as crises (Klebe et al., 2021). Crisis in particular demands a high need for constructive leadership to ensure follower health, because of the increase in health risks (Ahmed et al., 2020). At the same time, maintaining or even improving constructive leadership may become more difficult, as leaders themselves are affected by the same crisis-related stressors as their followers (i.e., high pressure or uncertainty; Charoensukmongkol \& Phungsoonthorn, 2020; Trougakos et al., 2020). Additionally, leaders may face demands such as high workloads, hindrances (Nicola et al., 2020), or having to lead across distances (Eurofound, 2020), making it even more difficult to continuously engage in staff-care.

In line with COR theory (Hobfoll et al., 2018), during a crisis individuals aim to protect their resources. Accordingly, COR would suggest that when leaders' well-being is threatened by the pandemic, they enter a defensive mode to preserve their resources and withdraw from staff-care. Because of increased demands, uncertainty, and pressure (Charoensukmongkol \& Phungsoonthorn, 2020; Trougakos et al., 2020), leaders focus on goal orientation and task fulfillment (Hannah et al., 2009) rather than protect- 
ing follower health. For example, when abruptly shifting to working from home, leaders may be occupied with the reorganization of tasks or technical obstacles, which may increase their strain. To protect their own resources, leaders may reduce health-promoting behavior such as reacting to follower strain or considering follower health when making decisions.

The field of studies investigating the effects of crises on leadership is limited: While charismatic leadership is more likely to occur in crisis (Bligh et al., 2005; Pillai, 1996), Geier (2016) found that transformational leadership decreases in extreme contexts, and that transactional leadership increases instead. Geier (2016) suggests this goes back to a lack of time and fewer opportunities to engage in transformational leadership in critical situations. Similarly, there is evidence that positive leadership is likely to decrease when leaders are stressed; during demanding times leaders lack the resources and capacities to continuously engage in positive behavior (Harms et al., 2017; Kaluza et al., 2020). We therefore postulate that leaders display less staff-care when the crisis is severe:

Hypothesis 3: Crisis severity is negatively related to staff-care.

Moreover, we postulate an indirect relationship between crisis severity and exhaustion via staff-care and self-care, as stressors and resources cross over from leaders to followers, which would be in line with the loss spirals postulated by COR theory (Hobfoll et al., 2018): When leaders are occupied with hindrance stressors (e.g., coping with technical obstacles) and with conquering the crisis, they lack the resources and capacities for staff-care. As leaders withdraw from protecting follower health and staff-care decreases, followers lack the necessary resources in terms of support and encouragement for self-care (e.g., taking breaks for recovery, detachment after work). In turn, when self-care decreases, followers may overlook health-related risks and have difficulty coping with demands related to the crisis and their exhaustion increases. This line of reasoning is supported by previous studies showing that the effect of staff-care on follower health is partially mediated by follower self-care (Franke et al., 2014; Horstmann, 2018).

Taken together, we propose that crisis severity is associated with lower staff-care, accompanied by lower self-care and in turn higher levels of exhaustion. We thus hypothesize the following:

Hypothesis 4: Crisis severity is indirectly related to exhaustion via staff-care and self-care. Higher levels of crisis severity relate to lower levels of staff-care, which relate to lower levels of self-care, which in turn relate to higher levels of follower exhaustion.

Moreover, crisis severity may relate not only to the extent, but also to the effectiveness of staff-care. While crises foster the impact of charismatic leadership (de Hoogh et al., 2004; Waldman et al., 2001), the impact of healthy leadership during crises is yet unknown. On the one hand, the benefit of staff-care may decrease, as followers may not be responsive while struggling with demands and coping with the crisis. Regarding secondary appraisal in transactional stress theory (Lazarus \& Folkman, 1984), when followers recognize a threat to workrelated goals, they might even consider it counterproductive when leaders put too much emphasis on health instead of conquering the crisis. Alternatively, employees may develop a higher need for and appreciate greater staff-care, because a crisis poses an acute threat to their well-being (Ahmed et al., 2020; Trougakos et al., 2020). This view is strongly supported by the "gain paradox principle" in COR theory, which states that resources gain value under circumstances of loss (Hobfoll et al., 2018). That is, because followers' resources are threatened during a crisis, their leaders' support becomes particularly relevant to compensate or prevent further loss. Because positive leadership provides guidance, encourages followers, and reduces ambiguities when crises threaten wellbeing, experienced strain might decrease (Diebig et al., 2016). Particularly during COVID-19, supervisor support can reduce uncertainties to protect follower health (Charoensukmongkol \& Phungsoonthorn, 2020). For example, when a team suffers from time pressure, staff-care may provide a resource to reduce or buffer pressure (e.g., providing support, encouraging followers to set priorities), consequently improving follower well-being.

In line with the "gain paradox principal" postulated in COR theory and similar evidence for charismatic leadership, we consider it as more likely that followers are in greater need of staff-care as an external resource when internal resources are threatened by the crisis:

Hypothesis 5: Crisis severity moderates the relationship between staff-care and exhaustion. The negative relationship is stronger when the crisis is more severe.

\section{COVID-19, Hindrances, and Crisis Severity}

We further sought to better understand how the COVID19 pandemic affects leadership and employee health by considering hindrance stressors as explaining factors for the degree of crisis severity. Depending on the industry, some employees may be affected more than others by the pandemic. We propose that employees whose work is more affected by the pandemic are also more likely to report hindrance stressors (i. e., stressors that are apprais- 


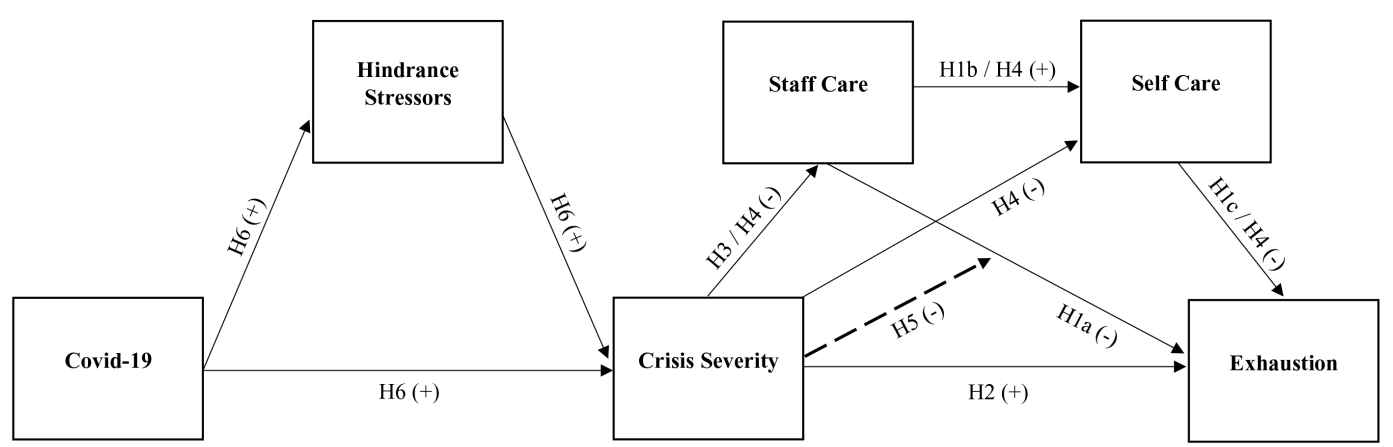

Figure 1. Conceptual model of the relationships between COVID-19, hindrance stressors, crisis severity, staff-care, self-care, and exhaustion. The dashed line represents the moderation.

ed as thwarting goal attainment; Cavanaugh et al., 2000). Many organizations had to interrupt daily work routines, reorganize, or even pause established processes altogether. For example, many employees immediately shifted to working from home, which required reorganizing workspace, communication channels, and daily operations at short notice. Some sectors have faced increasing demands in the pandemic, leading to staff shortages and increases in workload. Others have had to cope with stagnation because supply chains may be interrupted because of containment measures or bankruptcy of distributors (Eurofound, 2020; Nicola et al., 2020). These effects of the pandemic are likely experienced by affected employees as hindrances: The more an organization is affected by the pandemic, the more hindrance stressors can be expected in terms of interferences, hassles, and ambiguity in employees' work routines (Crawford et al., 2010; LePine et al., 2005).

In turn, hindrance stressors relate to a more severe crisis (i.e., high event strength in the sense of event systems theory; Morgeson et al., 2015), because hindrances may be threatening and harmful to goal achievement (Dawson et al., 2016). For example, abrupt local separation of teams, personnel shortage, and cancellation of events or delivery problems may lead to uncertainty or excessive demands, and thus to higher crisis severity. In contrast, when no hindrances occur or when work is even facilitated during the pandemic, crisis severity may be lower (i. e., low event strength; Morgeson et al., 2015). For example, digitalization may simplify communication processes or the cancellation of events may create extra time for other important tasks. Therefore, it is plausible that hindrances explain crisis severity.

Following event systems theory (Morgeson et al., 2015) and the fact that the COVID-19 pandemic as a trigger has led to increasing hindrances in several sectors (Nicola et al., 2020), we expect that hindrance stressors explain part of the relationship between the COVID-19 pandemic and crisis severity in the working environment:
Hypothesis 6: The COVID-19 pandemic is indirectly related to crisis severity via hindrance stressors.

In sum, we investigate crisis severity as a situational influence on HoL in the context of the COVID-19 pandemic (see the conceptual model in Figure 1). Drawing on COR theory (Hobfoll et al., 2018) and event systems theory (Morgeson et al., 2015), we expect an indirect relationship between the COVID-19 pandemic and crisis severity via hindrance stressors (H6), and a negative relationship between crisis severity and staff-care (H3). Moreover, we expect a direct relationship between crisis severity and follower exhaustion (H2) and an indirect relationship between crisis severity and follower exhaustion via staff-care and self-care $(\mathrm{H} 1 \mathrm{~b} / \mathrm{H} 1 \mathrm{c} / \mathrm{H} 4)$. We also expect that the relationship between staff-care and follower exhaustion (H1a) is stronger when the crisis is more severe (H5).

Whereas the negative crisis effects on follower health (Giorgi et al., 2015) and the mediating effects of staff-care on follower health via self-care found support in prepandemic research (Franke et al., 2014), examining the level and effectiveness of HoL in a highly critical period (i.e., the early phase of the pandemic) is of high novelty value and makes important contributions to the literature and the validation of the HoL concept.

\section{Method}

\section{Sample and Procedure}

The study was conducted as an online survey with two measurement points with a timelag of 1 week during the beginning of the COVID-19 pandemic in Germany. From mid-March 2020, the beginning of restrictions in Germany, up to mid-May 2020, participants were recruited through the authors' personal networks and online platforms. 
Table 1. Means, standard deviations and intercorrelations for COVID-19, hindrance stressors, crisis severity, staff-care, self-care, and exhaustion

\begin{tabular}{|c|c|c|c|c|c|c|c|c|c|}
\hline & & $M(S D)$ & 1 & 2 & 3 & 4 & 5 & 6 & 7 \\
\hline 1 & COVID-19 & $4.04(1.16)$ & & & & & & & \\
\hline 2 & Hindrance stressors & $3.00(0.89)$ & $.41 * *$ & $(.77)$ & & & & & \\
\hline 3 & Crisis severity & $2.72(0.88)$ & $.36 * *$ & $.35 * *$ & $(.80)$ & & & & \\
\hline 4 & Staff-care & $3.10(0.80)$ & -.03 & -.03 & $-.23 * \star$ & $(.91)$ & & & \\
\hline 5 & Self-care & $3.57(0.60)$ & .09 & .05 & $-.23 * \star$ & $.45^{\star \star}$ & (.83) & & \\
\hline 6 & Exhaustion t1 & $2.81(1.09)$ & .04 & -.01 & $.23 * \star$ & $-.28 * *$ & $-.49 * *$ & $(.90)$ & \\
\hline 7 & Exhaustion t2 & $2.74(1.07)$ & .09 & .03 & $.33 * \star$ & $-.31 * *$ & $-.28 * *$ & $.72 \star \star$ & (.88) \\
\hline
\end{tabular}

Note. $N_{t 1}=264 ; N_{t 2}=123 .{ }^{*} p<.01 . M$ and $S D$ represent mean and standard deviation. Cronbach's alpha in parentheses across the diagonals.

The sample consisted of $N=264$ employees at t1, with $N=123$ participating at t2. Age was measured in categories: Most participants in the sample $(53.4 \%)$ were between 25 and 34 years old $(19.7 \%<25$ years; $12.9 \%=$ 35 to 44 years; $9.5 \%=45$ to 54 years; $4.5 \%=55$ to 64 years), and most participants $(61.4 \%)$ were female. The participants worked in various sectors (e.g., public services, banking and finance, IT, health, research and education), and around $64 \%$ of them had an academic degree. The distribution of demographics was nearly identical at $\mathrm{t} 2$.

\section{Measures}

\section{The COVID-19 Pandemic}

To measure to what extent employees' work environment was affected by the COVID-19 pandemic, we used a single item: "My working situation is affected by COVID-19."

\section{Hindrance Stressors}

To measure work-related hindrance stressors in terms of specific hassles and obstacles arising from the pandemic, we adapted items from the "stressors" scale from the Instrument for Stress-Related Job Analysis (Clasen, 2019). Participants were advised to rate their current working situation. The scale included 5 items, such as "We have to re-organize a lot at short notice (e.g., events, meetings)" or "My work stagnates (e.g., because of delivery problems, cancellation of events or interruptions of operations)." Cronbach's alpha was $\alpha=.77$.

\section{Crisis Severity}

The severity of the crisis in the current working situation was measured using a self-developed scale adapted from a scale of perceived environmental dynamism by de Hoogh et al. (2004). Participants rated their current work situation with 5 items, such as "Currently, we work extremely hard to prevent or to overcome a crisis" or
"The current situation is unpredictable, and its outcome is uncertain." Cronbach's alpha was $\alpha=.80$.

\section{Health-Oriented Leadership}

We used the Health-Oriented Leadership scales by Pundt and Felfe (2017). The scale Staff-care included 18 items, e.g., "In the last days my direct supervisor noticed in a timely manner when I needed a break for recovery." Cronbach's alpha was $\alpha=.91$. Employee self-care was measured with 15 items, e.g., "In the last days I consciously paid attention to alarming health signals." Cronbach's alpha was $\alpha=.83$. Construct validity of the HoL scales was demonstrated in previous studies (Franke et al., 2014; Kaluza et al., 2021).

\section{Follower Exhaustion}

We used exhaustion as an indicator of follower strain. The subscale personal burnout from the German version of the Copenhagen Psychosocial Questionnaire (COPSOQ) by Nübling et al. (2006) with 5 items was used, including items such as "In the last days I have been emotionally exhausted" ( $\left.\alpha_{t 1}=.90 ; \alpha_{t 2}=.88\right)$.

All items were rated on a 5-point Likert scale from $1=$ not at all true to $5=$ completely true. Table 1 shows the means, standard deviations, and correlations for all study variables.

We conducted a CFA to test our measurement model. As recommended by Kishton and Widaman (1994), for self-care and staff-care we used item parceling based on subfacets of the HoL constructs (Franke et al., 2014). We compared the fit of our 5-factor model with competing 4-, 3-, and 1-factor models (see Table 2). The hypothesized 5factor model showed a better fit than the other models $\left(\chi^{2}\right.$ $=336(161), p<.001 ; \mathrm{CFI}=.925 ;$ RMSEA $=.064$; Table 2 ). The improvement in model fit was significant $\left(\Delta \chi^{2}=45 ; p\right.$ $<$.001), supporting the differentiation between five factors. 
Table 2. Confirmatory factor analysis

\begin{tabular}{lccccccc}
\hline Model & $\chi^{2}$ & $d f$ & $\chi^{2} / d f$ & CFI & RMSEA & $\Delta \chi^{2}$ & $\Delta d f$ \\
\hline 5 factors & 336 & 161 & 2.087 & .925 & .064 & .071 & 45 *** \\
4 factors & 381 & 165 & 2.309 & .907 & .899 & .073 & $22^{\star \star \star}$ \\
3 factors & 403 & 168 & 2.400 & .737 & .117 & $383^{\star \star \star}$ \\
1 factor & 786 & 171 & 4.597 & 3 \\
\hline
\end{tabular}

Note. $N=264.5$ factors: Hindrances, crisis, staff-care, self-care, exhaustion. 4 factors: Hindrances + crisis, staff-care, self-care, exhaustion. 3 factors: Hindrances + crisis, staff-care + self-care, exhaustion. 1 Factor: All items loading on one factor. CFI: comparative fit index. RMSEA: root mean square error of approximation. ${ }^{* \star *} p<.001$.

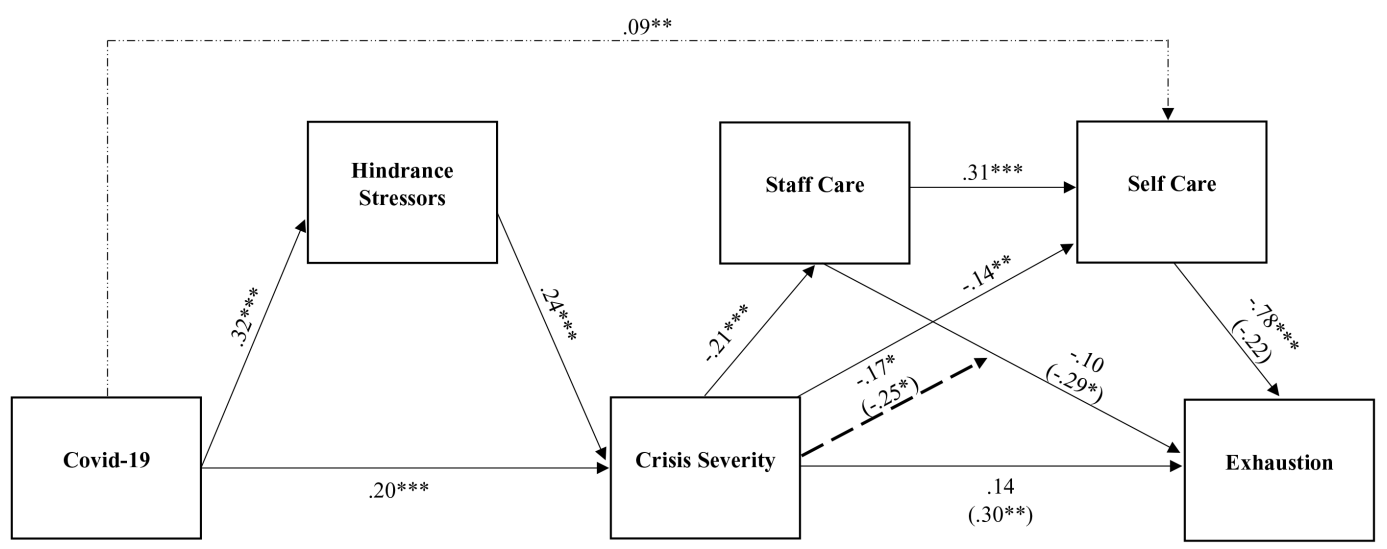

Figure 2. Final model of direct and indirect effects between COVID-19, hindrance stressors, crisis severity, staff-care, self-care and exhaustion at t1. The bold dashed line represents the moderation. The thin dashed line represents the additional path derived from model comparisons. Effects for exhaustion at $\mathrm{t} 2$ are in parentheses. ${ }^{*} p<.05,{ }^{* *} p<.01,{ }^{* * *} p<.001$.

\section{Analyses}

To test the interrelationships between study variables, we calculated path models using Mplus 8 (Muthén \& Muthén, 1998-2017). Because of the large number of items and model parameters relative to the sample size, we calculated a model with manifest variables and not a latent SEM (see Kline, 2011). Since our hypotheses specify various indirect relationships between crisis, HoL, and exhaustion, we compared our conceptual model with a less restrictive model that included all possible paths between variables as well as the interaction effect between staff-care and crisis on exhaustion. Results show that our conceptual model had a very good model fit $\left(\mathrm{Chi}^{2}\right.$ $=14.725(10), p=.142 ; \mathrm{CFI}=.982$; RMSEA $=.042)$, though not as good as the comparison model $\left(\mathrm{Chi}^{2}=1.233(4), p=\right.$ .873 ; CFI $=1.000$; RMSEA $=.000)$. Because the direct path between "COVID-19" and "self-care" considerably improved the fit $\left(\mathrm{Chi}^{2}=5.376(9), p=.800 ; \mathrm{CFI}=1.000\right.$; RMSEA $=.000)$, this path was included in our final model (Figure 2).

To strengthen the findings and to reduce the limitations of cross-sectional designs, we also conducted our analysis with exhaustion at $\mathrm{t} 2(N=123)$.

\section{Results}

Table 1 shows the means, standard deviations, and intercorrelations for all study variables. We first tested our hypotheses with the full sample $(N=264)$ with exhaustion at t1. The COVID-19 pandemic was positively related to hindrance stressors $(r=.41, p<.01)$ and crisis severity $(r=.36, p<.01)$. Crisis severity was positively related to hindrances $(r=.35, p<.01)$ and exhaustion $(r=$ $.23, p<.01)$, and negatively to staff-care $(r=-.23, p<.01)$ and self-care $(r=-.23, p<.01)$. In turn, staff-care and selfcare were positively related $(r=.45, p<.01)$, and both were negatively associated with exhaustion (staff-care $r=$ $-.28, p<.01$; self-care $r=-.49, p<.01$ ). Correlations with exhaustion at t2 differed only marginally (see Table 1 ). Figure 2 shows unstandardized coefficients for the direct and indirect relationships in the final path model.

First, we expected that both staff-care (H1a) and selfcare (H1c) would be negatively associated with follower exhaustion and positively with each other (H1b). Self-care was negatively related to exhaustion $(B=-.78, p<.001)$. Staff-care was not related to exhaustion in the path model $(B=-.10, p=.06)$, but showed a positive bivariate correlation with exhaustion $(r=-.28, p<.01$; Table 1$)$. In 


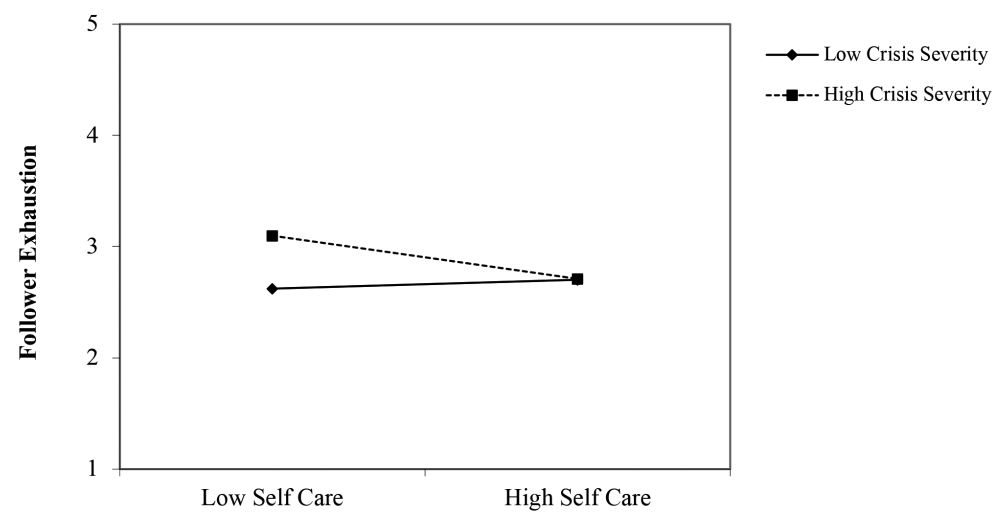

Figure 3. Two-way interaction of crisis severity and staffcare on exhaustion. line with our assumption, staff-care and self-care were positively related $(B=.31, p<.001)$. Thus, hypotheses $1 \mathrm{a}-\mathrm{c}$ were supported.

Second, as proposed in hypothesis 2, crisis severity was positively associated with exhaustion $(r=.23, p<.01$; Table 1), but in the path model crisis severity missed significance on the $5 \%$ level $(B=.14, p<.10)$. Thus, hypothesis 2 was supported.

Third, we expected that crisis severity would be negatively related to staff-care $(\mathrm{H} 3)$. The path model showed a negative relationship between crisis severity and staff-care $(B=-.21, p<.001)$. Thus, hypothesis 3 was supported.

Fourth, we expected that crisis severity would be indirectly related to exhaustion through staff-care and self-care (H4). In support of hypothesis 4 , the mediation analysis revealed an indirect relationship between crisis severity and exhaustion via staff-care and self-care $(B=$ $.05, S E=.02,95 \%$ CI $[.02 ; .08], p<.01$; Table 3$)$. The direct negative relationship between crisis severity and self-care was also significant $(B=-.14, p<.01)$.

Table 3. Specific indirect effects of (1) COVID-19 on crisis severity via hindrance stressors, (2) crisis severity on exhaustion via staff-care and self-care, and (3) COVID-19 on exhaustion via hindrance stressors, crisis severity, staff-care, and self-care

\begin{tabular}{lllllll}
\hline & Effect & $\begin{array}{c}\text { Boot } \\
\text { SE }\end{array}$ & LLCI & ULCl & $p$ \\
\hline $1 \quad \begin{array}{l}\text { COVID-19 } \rightarrow \text { hindrance stressors } \\
\rightarrow \text { crisis severity }\end{array}$ & .076 & .022 & .040 & .113 & .001 \\
2 & $\begin{array}{l}\text { Crisis severity } \rightarrow \text { staff-care } \rightarrow \\
\text { self-care } \rightarrow \text { exhaustion }\end{array}$ & .049 & .017 & .022 & .077 & .004 \\
$3 \quad \begin{array}{l}\text { CoVID-19 } \rightarrow \text { hindrance stressors } \\
\rightarrow \text { crisis severity } \rightarrow \text { staff-care } \rightarrow \\
\text { self-care } \rightarrow \text { exhaustion }\end{array}$ & .004 & .002 & .001 & .006 & .021 \\
\hline
\end{tabular}

Note. $N=264$. Boot $S E$ represents the bootstrapped standard error. LLC and $\mathrm{ULCl}$ represent the lower-limit and upper-limit of the $95 \%$ confidence interval.
Fifth, we expected that crisis severity would strengthen the negative relationship between staff-care and exhaustion (H5). The moderation analysis revealed a significant interaction between crisis severity and staff-care on exhaustion $(B=-.17, p<.05)$. As Figure 3 shows, the relationship was stronger when the crisis was more severe. A simple slopes analysis showed that the relationship between staff-care and exhaustion was not significant at low levels of crisis severity (i. e., $\mathrm{M}-1 S D ; B=.05 ; p$ $=.657$ ), but negative and significant at high levels of crisis severity $(\mathrm{M}+1 S D ; B=-.24 ; p<.05)$. Thus, hypothesis 5 was supported.

Finally, we proposed that hindrance stressors would partly explain the relationship between the COVID-19 pandemic and crisis severity (H6). Results revealed a positive relationship between the COVID-19 pandemic and hindrance stressors $(B=.32, p<.001)$, and a positive relationship between hindrance stressors and crisis severity $(B=.24, p<.001$; Figure 2$)$. Moreover, we found a positive relationship between the COVID-19 pandemic and crisis severity $(B=.20, p<.001)$. In support of hypothesis 6 , the mediation analysis showed an indirect relationship between the COVID-19 pandemic and crisis severity via hindrance stressors $(B=.08 ; S E=.02,95 \% \mathrm{CI}$ $[.04 ; .11], p<.01$; Table 3$)$. The indirect relationship between the pandemic and follower exhaustion via hindrance stressors, crisis severity, staff-care and selfcare was significant $(B=.004, S E=.002,95 \%$ CI [.001; .006], $p<.05$; Table 3).

In a second step, we tested our hypotheses regarding exhaustion (1a, 1c, 2, 4, and 5) again with exhaustion at t2 $(N=123)$. Missing values were compensated through full information maximum likelihood (FIML). The corresponding path coefficients are reported in parentheses in Figure 2. Most of the relationships were similar to the t1 findings: Again, crisis severity was positively $(B=.30, p<$ $.01)$, and staff-care negatively $(B=-.29, p=.05)$ related to follower exhaustion, supporting Hypotheses 1a and 2. In support of hypothesis 5 , crisis severity strengthened the 
negative relationship between staff-care and exhaustion $(B=-.25, p<.05)$.

Although the correlation between self-care and exhaustion at $\mathrm{t} 2$ was negative $(r=-.28, p<.01)$, supporting hypothesis $1 \mathrm{c}$, the coefficient in the path model was not significant $(B=-.22, p=.23)$. Thus, only hypothesis 4 was not supported at $\mathrm{t} 2$.

\section{Discussion}

This study examined the ways crises relate to HoL and its effectiveness in the context of the COVID-19 pandemic. The results support the postulated negative relationships between HoL and follower exhaustion during the pandemic and suggest that HoL gains importance during crises: Crisis severity was related to lower staff-care, but staff-care was more effective with high crisis severity.

First, the negative relationships of staff-care and selfcare with follower exhaustion replicate and further validate previous findings (Arnold \& Rigotti, 2021; Horstmann, 2018; Klug et al., 2019). Also in line with previous research, our study shows a positive association between staff-care and self-care (Franke et al., 2014; Horstmann, 2018): Staff-care goes along not only with follower health, but also with self-care, which in turn relates to follower health.

Second, drawing upon event systems theory (Morgeson et al., 2015) and COR theory (Hobfoll et al., 2018), we expected that crisis severity would be positively related to follower exhaustion. In line with our expectations, we could replicate the first findings of negative crisis effects on follower health from the medical sector (LuceñoMoreno et al., 2020; Wu et al., 2020) for employees across various occupations. In line with event systems theory (Morgeson et al., 2015), we showed that employees who work in environments with high crisis severity report higher exhaustion. Thus, the threatening and uncertain nature of a crisis is associated with impaired follower health.

Third, in line with previous research (Geier, 2016; Harms et al., 2017; Kaluza et al., 2020), we found that staff-care was lower when crisis severity was high. A crisis seems to impair leaders' emotional and cognitive capacities because of increasing stress, pressure, and workload, so that leaders are not able to continuously engage in staff-care. In turn, this relates to lower self-care and higher exhaustion among followers. It should be noted that the indirect relationship between crisis and exhaustion via self-care was supported only cross-sectionally, probably because of a lack of statistical power, as the bivariate correlation between self-care and exhaustion was clearly significant. Most importantly, we found that staff-care was more effective when the crisis was more severe, supporting the gain paradox principle in COR theory (Hobfoll et al., 2018). Similar findings have been shown for charismatic leadership (de Hoogh et al., 2004; Waldman et al., 2001). Staff-care has the chance to flourish in critical periods and to make a clear difference for follower health, because followers seem to be particularly in need of and receptive to health promotion in crisis. This is a crucial finding because displaying staffcare seems to become more difficult in crisis, albeit simultaneously more important. Our study underlines the notion that leadership is dependent on the situation (Geier, 2016; Halverson et al., 2004), and follows the call for the identification of situational influences on leadership (Hannah \& Parry, 2014; Peus et al., 2013).

Finally, our study provides insights into factors that can explain the degree of crisis severity as a precursor of healthy leadership. Results revealed that hindrance stressors partly explain the relationship between the COVID19 pandemic and crisis severity. In line with event systems theory, the crisis is reported as more severe (i.e., high event strength; Morgeson et al., 2015) by those employees who report a strong influence of the pandemic on their work and in turn more hindrances. This indicates that hindrance stressors can partly explain how the COVID-19 pandemic manifests itself as a severe workplace crisis with negative consequences for leadership and employee health.

\section{Theoretical Implications}

By investigating the role of crises in the context of the COVID-19 pandemic, this study adds an important situational predictor and moderator to the framework of HoL (see Rudolph, Murphy et al., 2020) and contributes to the current debate on the pandemic as a critical situational influence on leadership (Budhwar \& Cumming, 2020; Rudolph, Allan et al., 2020). The study reveals a serious dilemma for healthy leadership in crisis: While it seems to be more difficult for leaders to engage in health-promoting behavior, at the same time it becomes even more important for their followers' health. For our theoretical understanding of leadership, this finding underlines the importance of considering different ways through which situational influences may operate, because the same situation can have different, even paradoxical, effects depending on whether it is specified as a predictor or as a moderator of leadership.

Our study combines event systems theory (Morgeson et al., 2015) with COR theory (Hobfoll, 1989) to contribute to 
knowledge about crisis as a predictor and moderator of leadership, and healthy leadership in particular, where prior studies (Arnold \& Rigotti, 2021; Franke et al., 2014; Klug et al., 2019) did not control for situational influences. In the sense of event systems theory, our findings support the notion that the pandemic is a novel, disruptive, and critical event that affects leader and follower behavior through the degree of event strength, as crisis severity was related to reduced staff-care and moderated its effectiveness. Crisis severity was also directly related to follower health. COR theory explains the stress mechanisms underlying the effects of crisis severity: Because crises threaten the resources of both leaders and followers, leaders lack the capacities to engage in staff-care, which relates to lower self-care and lower follower health. This finding supports the assumption in COR of loss spirals in light of the COVID-19 pandemic (Hobfoll et al., 2018). Moreover, the pattern of relationships between crisis severity, staff-care, and follower health reflects the resource gain paradox, as staff-care is lower among employees during a severe crisis, but at the same time more strongly related to well-being. These findings show that HoL particularly gains importance when followers' well-being is threatened (see also Klebe et al., 2021). Further theoretical and empirical work is needed to understand how these patterns evolve over time with increasing crisis duration, for example, with respect to escalating loss spirals or adaptation.

Finally, in line with event systems theory (Morgeson et al., 2015), the study supports the notion that event strength is a continuum in the sense that crisis severity differs between employees and organizations. Again, our study highlights stress as an underlying mechanism, as work-related hindrances seem to explain how the macrolevel COVID-19 pandemic relates to crisis on the microlevel (organization or team). Since crises represent complex events, further theory development should consider additional factors that may explain crisis severity, such as financial risks or personnel shortage.

\section{Practical Implications}

Regarding practical implications, our findings suggest that leaders should be aware of the negative crisis effects, specifically the COVID-19 pandemic effects, on leadership and follower health, but also of the benefits of staffcare, particularly in critical situations. Organizations should remind leaders of their responsibilities for their own and their followers' health and should invest in leadership development and occupational health promotion (Kelloway \& Barling, 2010; Nielsen \& Taris, 2019). By implementing HoL processes (Elprana et al., 2016), organizations can systematically examine and feedback the levels of HoL on the team level and develop recommendations for concrete actions under qualified guidance, particularly for critical periods. In doing so, organizations can foster staff-care as an important prerequisite for follower health in severe crises. Generally, HoL interventions are a promising strategy for addressing mental health in the workplace (Stuber et al., 2021). Organizations can, for example, specifically train leaders' awareness for health-related warning signals in crisis, when priorities may shift from a person-oriented to a more task-oriented perspective. By investing in leaders' crisis management, health awareness, and health promotion, organizations can help to prevent leadership and follower health from deteriorating. Particularly regarding the pandemic, leaders should be aware that employees are exposed to specific risks. It is important that remote leaders too feel responsible for their followers' health (value), pay attention to health-related warning signals (awareness), and invite followers to inform them about their health risks at work (behavior; Efimov et al., 2020).

Furthermore, our study identifies hindrance stressors as an important correlate of crisis severity. Organizations should aim at reducing work-related hindrances, support leaders and followers in coping with them to buffer the repercussions of crisis at the workplace, and thus avoid negative consequences for leadership and well-being. For example, organizations can provide the necessary equipment to work from home, ensure transparent communication of occurring problems or provide teams with the appropriate staff according to needs. In doing so, organizations can reduce hindrances and therewith crisis severity, which may ensure capacities for further COVID19 waves and other critical periods.

\section{Limitations and Recommendations for Future Research}

The study has some limitations that should be considered. First, our study covered only short-term relationships between HoL and followers during the COVID-19 pandemic. Particularly during the pandemic, organizations need to know the long-term effects in order to increase leaders' willingness to continuously consider and foster follower health. Because staff-care values followers' needs, its effectiveness may especially pay off in the long run, and sustainable effects are expected that help employees to cope with rapidly changing working conditions and large-scale crises (Klebe et al., 2021). It is also conceivable that leaders and followers get used to volatile 
working conditions in long-term crises (e.g., further COVID-19 waves), so that both may deteriorate in the short term, but improve again in the long term.

Second, in addition to cross-sectional analyses, we tested relationships of crisis and leadership with exhaustion with a time lag of 1 week for a subsample. However, a high dropout rate reduced the statistical power, so that at least our findings for self-care need further validation. Additionally, the appropriate time interval to measure relationships with exhaustion is debatable. According to Maslach et al. (2001), exhaustion is a prolonged response to chronic job stressors, so that a longer interval may be more appropriate to detect effects. However, other studies revealed associations even on a daily level (e.g., Derks et al., 2014; Klusmann et al., 2021), indicating that also short-term effects are likely. These effects may be overlooked when intervals are too long. The dilemma of choosing the appropriate time interval is also discussed in the literature: Whereas too-short intervals may lead to the conclusion that no effects exist because complaints that develop over a longer period of time cannot be captured, too-long intervals may underestimate relationships and the true causal impact (Mohr \& Semmer, 2002; Zapf et al., 1996).

Further, longitudinal studies are needed to confirm mediation effects, as the current design limits interpretations in terms of causal relationships. While the sequence of the serial mediators staff-care and self-care between crisis and exhaustion was theoretically justified (Franke et al., 2014; Horstmann, 2018), the current design cannot assess the "true" sequence between the pandemic, hindrance stressors, and crisis severity (e.g., employees might deduct the extent to which COVID-19 impacts their work from levels of hindrances).

Third, results may be affected by common method bias (Podsakoff et al., 2003), as all variables were rated by employees and may have been influenced by subjective perceptions. Future studies should collect data from different perspectives (e.g., leaders' ratings of crisis severity, coworkers' ratings of staff-care) and complement results with more objective health indicators (e.g., sick leave, absenteeism). Nevertheless, it is important to acknowledge the relevance of employee perceptions of leadership and its effects (Perko et al., 2016), as they may be more relevant for health than objective or independent measures of leadership. This is in line with stress theories that emphasize subjective appraisal processes (Lazarus \& Folkman, 1984). Future studies could test this reasoning by comparing the effects of follower perceptions with selfreports from leaders or observer ratings of leadership.

Fourth, the sample is not representative of the German workforce. Participants were rather young, and most had academic degrees. Particularly employees who are highly affected by the crisis may have been underrepresented, as they do not have enough capacities to take part in survey studies because of strain and workload. Therefore, the current findings may even underestimate the level of exhaustion in the German workforce. However, while selection bias may have affected the levels of study variables (e.g., crisis severity, exhaustion), relationships among variables should be unaffected.

Fifth, besides the hypothesized paths, there may be other non-work-related influences of the pandemic on follower health. For example, our final empirical model includes a direct path between the COVID-19 pandemic and employee self-care. Therefore, it is conceivable that other issues hinder followers from engaging in self-care in the pandemic (e.g., childcare while working from home). Future research should therefore investigate the extent to which the pandemic affects self-care apart from job characteristics.

Finally, using a single item to assess how much employees were affected by the COVID-19 pandemic is a limitation regarding psychometric properties. However, this item primarily served as an assessment to reflect the extent to which crisis severity as our central predictor and moderator actually related to the pandemic instead of other factors in the organization. Whether employees' work is affected by the pandemic reflects an objective fact rather than a psychological construct, so that a single item may be appropriate in this case. Correlation analysis supported this notion, showing that the COVID-19 item was related to both hindrance stressors and crisis severity. Nevertheless, future studies could investigate whether employees are affected by the pandemic with a more differentiated scale.

\section{Conclusion}

This study is the first to investigate HoL and its effectiveness during the COVID-19 pandemic and thus contributes to the deeper understanding of crisis as a situational influence on leadership. Results suggest that staff-care is lower but at the same time more effective in crises. Findings suggest that organizations should aim at reducing work-related hindrances to reduce crisis severity with its negative consequences and encourage leaders to display HoL, particularly in severe crises, to protect follower health.

\section{References}

Ahmed, F., Zhao, F., \& Faraz, N. A. (2020). How and when does inclusive leadership curb psychological distress during a crisis? 
Evidence from the COVID-19 outbreak. Frontiers in Psychology, 11. https://doi.org/10.3389/fpsyg.2020.01898

Arnold, M., \& Rigotti, T. (2021). Is it getting better or worse? Health-oriented leadership and psychological capital as resources for sustained health in newcomers. Applied Psychology, 70(2), $709-737$.

Bligh, M. C., Kohles, J. C., \& Pillai, R. (2005). Crisis and charisma in the California recall election. Leadership, 1(3), 323-352.

Brammer, S., \& Clark, T. (2020). COVID-19 and management education: Reflections on challenges, opportunities, and potential futures. British Journal of Management, 31(3), 453- 456.

Budhwar, P., \& Cumming, D. (2020). New directions in management research and communication: Lessons from the COVID-19 pandemic. British Journal of Management, 31(3), 441 - 443.

Bundy, J., \& Pfarrer, M. D. (2015). A burden of responsibility: The role of social approval at the onset of a crisis. Academy of Management Review, 40(3), 345-369.

Cavanaugh, M. A., Boswell, W. R., Roehling, M. V., \& Boudreau, J. W. (2000). An empirical examination of self-reported work stress among U.S. managers. Journal of Applied Psychology, 85(1), $65-74$.

Charoensukmongkol, P., \& Phungsoonthorn, T. (2020). The effectiveness of supervisor support in lessening perceived uncertainties and emotional exhaustion of university employees during the COVID-19 crisis: The constraining role of organizational intransigence. The Journal of General Psychology. https:// doi.org/10.1080/00221309.2020.1795613

Clasen, J. (2019). ISTA-F - Instrument zur stressbezogenen Tätigkeitsanalyse bei Freelancern (Verfahrensdokumentation aus PSYNDEX Tests-Nr. 9007847 und Fragebogen [Instrument for stress-related job analysis for freelancers (Procedure Documentation from PSYNDEX test no. 9007847 and questionnaire)]. ZPID.

Crawford, E. R., Lepine, J. A., \& Rich, B. L. (2010). Linking job demands and resources to employee engagement and burnout: A theoretical extension and meta-analytic test. The Journal of Applied Psychology, 95(5), 834-848.

Dawson, K. M., O'Brien, K. E., \& Beehr, T. A. (2016). The role of hindrance stressors in the job demand-control-support model of occupational stress: A proposed theory revision. Journal of Organizational Behavior, 37(3), $397-415$.

de Hoogh, A., den Hartog, D. N., Koopman, P., Thierry, H., van den Berg, P., van der Weide, J., \& Wilderom, C. (2004). Charismatic leadership, environmental dynamism, and performance. European Journal of Work and Organizational Psychology, 13(4), 447-471.

Demerouti, E., Bakker, A. B., Nachreiner, F., \& Schaufeli, W. B. (2001). The job-demands-resources model of burnout. Journal of Applied Psychology, 86(3), 499-512.

Derks, D., van Mierlo, H., \& Schmitz, E. B. (2014). A diary study on work-related smartphone use, psychological detachment and exhaustion: Examining the role of the perceived segmentation norm. Journal of Occupational Health Psychology, 19(1), $74-84$.

Diebig, M., Bormann, K. C., \& Rowold, J. (2016). A double-edged sword: Relationship between full-range leadership behaviors and followers' hair cortisol level. The Leadership Quarterly, 27(4), 684-696.

Efimov, I., Harth, V., \& Mache, S. (2020). Health-oriented self- and employee leadership in virtual teams: A qualitative study with virtual leaders. International Journal of Environmental Research and Public Health, 17(18). https://doi.org/10.3390/ ijerph17186519

Elprana, G., Felfe, J., \& Franke, F. (2016). Gesundheitsförderliche Führung diagnostizieren und umsetzen [Diagnose and implement health-oriented leadership). In J. Felfe \& R. van Dick (Eds.), Handbuch Mitarbeiterführung (pp. 143 -156). Springer.
Eurofound. (2020). Living, working and COVID-19 - First findings April 2020. Author.

Franke, F., Felfe, J., \& Pundt, A. (2014). The impact of healthoriented leadership on follower health: Development and test of a new instrument measuring health-promoting leadership. Zeitschrift Für Personalforschung, 28, 139-161.

Galbraith, N., Boyda, D., McFeeters, D., \& Hassan, T. (2020). The mental health of doctors during the COVID-19 pandemic. BJPsych Bulletin, 45(2), $93-97$.

Geier, M. T. (2016). Leadership in extreme contexts. Journal of Leadership \& Organizational Studies, 23(3), 234-247.

Giorgi, G., Arcangeli, G., Mucci, N., \& Cupelli, V. (2015). Economic stress in the workplace: The impact of fear of the crisis on mental health. Work, 51(1), 135-142.

Halverson, S. K., Murphy, S. E., \& Riggio, R. E. (2004). Charismatic leadership in crisis situations. Small Group Research, 35(5), $495-514$.

Hannah, S. T., \& Parry, K. W. (2014). Leadership in extreme contexts. Oxford University Press.

Hannah, S. T., Uhl-Bien, M., Avolio, B. J., \& Cavarretta, F. L. (2009). A framework for examining leadership in extreme contexts. The Leadership Quarterly, 20(6), 897 - 919.

Harms, P. D., Credé, M., Tynan, M., Leon, M., \& Jeung, W. (2017). Leadership and stress: A meta-analytic review. The Leadership Quarterly, 28(1), 178-194.

Hobfoll, S. E. (1989). Conservation of resources: A new attempt at conceptualizing stress. American Psychologist, 44(3), 513- 524.

Hobfoll, S. E., Halbesleben, J., Neveu, J.-P., \& Westman, M. (2018). Conservation of resources in the organizational context: The reality of resources and their consequences. Annual Review of Organizational Psychology and Organizational Behavior, 5(1), $103-128$

Horstmann, D. (2018). Enhancing employee self-care. European Journal of Health Psychology, 25(3), 96-106.

Kaluza, A. J., Boer, D., Buengeler, C., \& van Dick, R. (2020). Leadership behaviour and leader self-reported well-being: A review, integration and meta-analytic examination. Work \& Stress, 34(1), 34-56.

Kaluza, A. J., Weber, F., van Dick, R., \& Junker, N. M. (2021). When and how health-oriented leadership relates to employee wellbeing: The role of expectations, self-care, and LMX. Journal of Applied Social Psychology, 51, 404-424.

Kelloway, E. K., \& Barling, J. (2010). Leadership development as an intervention in occupational health psychology. Work \& Stress, 24(3), $260-279$.

Kishton, J. M., \& Widaman, K. F. (1994). Unidimensional versus domain representative parceling of questionnaire items: An empirical example. Educational and Psychological Measurement, 54(3), $757-765$.

Klebe, L., Felfe, J., \& Klug, K. (2021). Healthy leadership in turbulent times: The effectiveness of health-oriented leadership in crisis. British Journal of Management, 0, 1-16. https:// doi.org/10.1111/1467-8551.12498

Kline, R. B. (2011). Principles and practice of structural equation modeling (3rd ed.). Guilford.

Klug, K., Felfe, J., \& Krick, A. (2019). Caring for oneself or for others? How consistent and inconsistent profiles of healthoriented leadership are related to follower strain and health. Frontiers in Psychology, 10. https://doi.org/10.3389/fpsyg. 2019.02456

Klusmann, U., Aldrup, K., Schmidt, J., \& Lüdtke, O. (2021). Is emotional exhaustion only the result of work experiences? A diary study on daily hassles and uplifts in different life domains. Anxiety, Stress, and Coping, 34(2), 173-190.

Köppe, C., Kammerhoff, J., \& Schütz, A. (2018). Leader-follower crossover: Exhaustion predicts somatic complaints via staff- 
care behavior. Journal of Managerial Psychology, 33(3), $297-$ 310.

Lazarus, R. S., \& Folkman, S. (1984). Stress, appraisal, and coping. Springer.

LePine, J. A., Podsakoff, N. P., \& LePine, M. A. (2005). A metaanalytic test of the challenge stressor-hindrance stressor framework: An explanation for inconsistent relationships among stressors and performance. Academy of Management Journal, 48(5), $764-775$.

Luceño-Moreno, L., Talavera-Velasco, B., García-Albuerne, Y., \& Martín-García, J. (2020). Symptoms of posttraumatic stress, anxiety, depression, levels of resilience and burnout in spanish health personnel during the COVID-19 pandemic. International Journal of Environmental Research and Public Health, 17(15), 5514.

Maslach, C., Schaufeli, W. B., \& Leiter, M. P. (2001). Job burnout. Annual Review of Psychology, 52, 397- 422.

Mohr, G., \& Semmer, N. K. (2002). Arbeit und Gesundheit: Kontroversen zu Person und Situation [Work and health: Controversies on person and situation]. Psychologische Rundschau, 53(2), $77-84$.

Morgeson, F. P., Mitchell, T. R., \& Liu, D. (2015). Event system theory: An event-oriented approach to the organizational sciences. Academy of Management Review, 40(4), 515- 537.

Mucci, N., Giorgi, G., Roncaioli, M., Fiz Perez, J., \& Arcangeli, G. (2016). The correlation between stress and economic crisis: A systematic review. Neuropsychiatric Disease and Treatment, 12, $983-993$.

Mumford, M. D., Friedrich, T. L., Caughron, J. J., \& Byrne, C. L. (2007). Leader cognition in real-world settings: How do leaders think about crises? The Leadership Quarterly, 18(6), 515-543.

Muthén, L. K., \& Muthén, B. O. (1998-2017). Mplus user's guide (8th ed.). Author.

Nicola, M., Alsafi, Z., Sohrabi, C., Kerwan, A., Al-Jabir, A., Iosifidis, C., Agha, M., \& Agha, R. (2020). The socio-economic implications of the coronavirus pandemic (COVID-19): A review. International Journal of Surgery, 78, 185-193.

Nielsen, K., \& Taris, T. W. (2019). Leading well: Challenges to researching leadership in occupational health psychology - and some ways forward. Work \& Stress, 33(2), 107-118.

Nübling, M., Stößel, U., Hasselhorn, H.-M., Michaelis, M., \& Hofmann, F. (2006). Measuring psychological stress and strain at work - Evaluation of the COPSOQ Questionnaire in Germany. GMS Psycho-Social Medicine, 3, 1-14.

Perko, K., Kinnunen, U., Tolvanen, A., \& Feldt, T. (2016). Investigating occupational well-being and leadership from a personcentred longitudinal approach: Congruence of well-being and perceived leadership. European Journal of Work and Organizational Psychology, 25(1), $105-119$.

Peus, C., Braun, S., \& Frey, D. (2013). Situation-based measurement of the full range of leadership model: Development and validation of a situational judgment test. The Leadership Quarterly, 24(5), $777-795$.

Pillai, R. (1996). Crisis and the emergence of charismatic leadership in groups: An experimental investigation. Journal of Applied Social Psychology, 26(6), 543-562.

Podsakoff, P. M., MacKenzie, S. B., Lee, J.-Y., \& Podsakoff, N. P. (2003). Common method biases in behavioral research: A critical review of the literature and recommended remedies. The Journal of Applied Psychology, 88(5), 879 - 903.
Pundt, F., \& Felfe, J. (2017). Health-oriented Leadership. Instrument zur Erfassung gesundheitsförderlicher Führung [Instrument for recording health-oriented leadership. Hogrefe.

Rudolph, C. W., Allan, B., Clark, M., Hirschi, A., Kunze, F., Shockley, K., Shoss, M., Sonnentag, S., \& Zacher, H. (2020). Pandemics: Implications for research and practice in industrial and organizational psychology. Industrial and Organizational Psychology, $14,1-35$.

Rudolph, C. W., Murphy, L. D., \& Zacher, H. (2020). A systematic review and critique of research on "healthy leadership." The Leadership Quarterly, 31(1). https://doi.org/10.1016/j.leaqua. 2019.101335

Stuber, F., Seifried-Dübon, T., Rieger, M. A., Gündel, H., Ruhle, S., Zipfel, S., \& Junne, F. (2021). The effectiveness of healthoriented leadership interventions for the improvement of mental health of employees in the health care sector: A systematic review. International Archives of Occupational and Environmental Health, 94(2), $203-220$.

Trougakos, J. P., Chawla, N., \& McCarthy, J. M. (2020). Working in a pandemic: Exploring the impact of COVID-19 health anxiety on work, family, and health outcomes. The Journal of Applied Psychology, 105(11), 1234-1245.

Vincent-Höper, S., \& Stein, M. (2019). The role of leaders in designing employees' work characteristics: Validation of the Health- and Development-Promoting Leadership Behavior Questionnaire. Frontiers in Psychology, 10. https://doi.org/10. 3389/fpsyg. 2019.01049

Waldman, D. A., Ramírez, G. G., \& House, R. J. (2001). Does leadership matter? CEO leadership attributes and profitability under conditions of perceived environmental uncertainty. Academy of Management Journal, 44(1), 134-143.

Wu, W., Zhang, Y., Wang, P., Zhang, L., Wang, G., Lei, G., Xiao, Q., Cao, X., Bian, Y., Xie, S., Huang, F., Luo, N., Zhang, J., \& Luo, M. (2020). Psychological stress of medical staffs during outbreak of COVID-19 and adjustment strategy. Journal of Medical Virology, 92, $1962-1970$.

Zapf, D., Dormann, C., \& Frese, M. (1996). Longitudinal studies in organizational stress research: A review of the literature with reference to methodological issues. Journal of Occupational Health Psychology, 1(2), 145-169.

\section{History}

Received January 8, 2021

Revision received July 8, 2021

\section{Funding}

Open access publication enabled by Helmut Schmidt University / University of the Federal Armed Forces Hamburg.

\section{ORCID}

Laura Klebe

(DD https://orcid.org/0000-0001-7260-088X

\section{Laura Klebe}

Department of Work, Organizational and Economic Psychology

Helmut Schmidt University

University of the Federal Armed Forces Hamburg

Holstenhofweg 85

22043 Hamburg

Germany

klebe@hsu-hh.de 